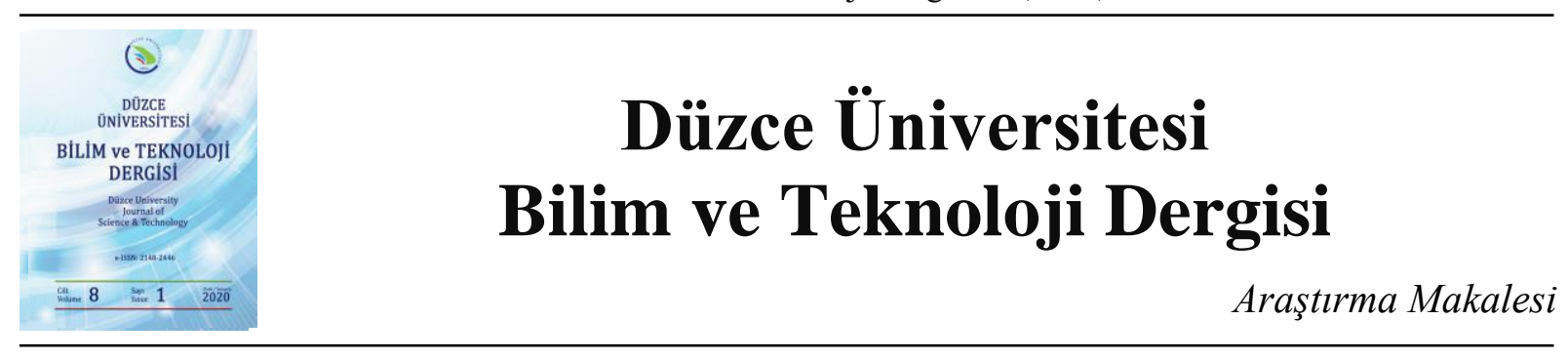

\title{
Web Tabanlı Bitki Bilgi Sitemi (BBS): Karadeniz Teknik Üniversitesi Kanuni Yerleşkesi Örneği
}

\author{
Kamber Can ALKİŞ ${ }^{\text {a,* }}$, (D) Saliha ÜNVER OKAN ${ }^{\mathrm{a}}$ \\ ${ }^{a}$ Orman Mühendisliği Bölümü, Orman Fakültesi, Karadeniz Teknik Üniversitesi, Trabzon, TÜRKIYYE \\ * Sorumlu yazarin e-posta adresi: kcakca2015@gmail.com
}

DOI: 10.29130/dubited.594972

\begin{abstract}
ÖZET
Günümüzde, şehir yaşamındaki stres, beton çevre, trafik ve kirlilik gibi olumsuz yaşam koşulları nedeniyle insanların bu alanlardan uzaklaşarak doğanın sunduğu doğal güzelliklerden yararlanma istekleri artmaktadır. Eğlenme ya da dinlenme amaçlı olarak ziyaret edilen; milli park, tabiat parkı, botanik parkı ya da arboretum sahalarında insanlar çok sayıda ve farklı bitki türleriyle karşılaşıllar. Daha önce değişik milli park, botanik parkları ve üniversite kampüslerinde yapılan gözlemlerde ziyaretçilerin ve kullanıcıların/öğrencilerin birçoğunun alanda bulunan bitki türlerinin isim ve özellikleri hakkında bilgi sahibi olmak istedikleri gözlemlenmiştir. $\mathrm{Bu}$ çalışmada, gelişen teknoloji ile kullanımı yaygınlaşmakta olan "Open Data" kavramından esinlenerek bitkilerin botanik özelliklerini içeren kare kodlar oluşturulması ve kullanıcıların mobil cihazları aracılı̆ı̆ıla bu bilgilere direk ulaşımını sağlayan bir yazılım geliş̧irilmesi amaçlanmıştır. Çalışma alanı olarak çok sayıda değişik ağaç, ağaççı ve çalı türü barındıran Karadeniz Teknik Üniversitesi Kanuni Kampüsü seçilmiştir. Kampüste en yaygın olarak bulunan 13 ağaç türünün botanik özellikleri, görselleri ve konumlarını içeren bir veri tabanı oluşturulmuş ve her biri için kare kod geliştirilmiştir. Yazılım, Karadeniz Teknik Üniversitesi web ara yüzünden yararlanarak Leaflet aracı yardımıyla HTML editörlerinden Visual Studio Code programında yazılmış̧ır. Kullanıcıların mobil cihazları ile kare kodların barındırdığı öznitelik bilgilerine ve OpenStreetMap açık kaynaklı kod sistemi ile konumsal bilgilerine kolaylıkla ulaşabilmesi sağlanmıştır. Bu çalışma kapsamında geliştirilen Web-BBS programı, çok sayıda ziyaretçi çeken değişik bitki müzeleri için örnek teşkil edecektir.
\end{abstract}

Anahtar Kelimeler: Açık kaynakll yazılım, Leaflet aracı, OpenStreetMap sistemi,

\section{Web Based Plant Information System: The Case of Karadeniz Technical University Kanuni Campus}

\begin{abstract}
Nowadays, because of the negative life conditions such as stress, concrete environment, traffic and pollution in urban life, people's desire to benefit from the natural beauties offered by nature increases. People visit to relax in the national park, nature park, botanical park or arboretum areas where they encounter numerous and different plant species. In previous observations made in these areas and university campuses, it was observed that many of the visitors and users / students wanted to have information about the names and characteristics of the plant species in the area. In this study, it is aimed to create a code which includes botanical characteristics of the plants and to develop a program that allows the direct access of the users to this information via their mobile devices by utilizing open information systems, which are becoming more and more widespread. Karadeniz Technical University Kanuni Campus, which has many tree, tree and shrub species, was chosen as the study area. First of all, a database including the botanical characteristics, images and locations of the 13 most common tree species on campus has been created and the QR has been developed for each. The program is written in Visual Studio
\end{abstract}


Code program from HTML editors using Leaflet tool by using web interface of Karadeniz Technical University. I was provided to access to attribute information in the QR using mobile devices and spatial information provided by the OpenStreetMap open source code system. The program developed within the scope of this study will serve as an example for various plant museums attracting many visitors.

Keywords: Open source software, Leaflet, OpenStreetMap

\section{GIRIS}

Canlı ve cansız pek çok öğeden oluşan orman ekosistemi pek çok disiplin için değişik bilgilere ulaşılmasını sağlayan önemli bir kaynaktır. Günümüzde teknolojide yaşanan gelişmeler sonucu, doğadan elde edilen bu bilgilerin aktarımında dijital sunum kullanımı yaygınlaşmıştır. Toplumlar bilgi toplumu olabilmek için tüm hizmet sektörlerinde bilgiye sahip olma ve bilgiyi verimli kullanma zorunluluğu duymaya başlamışlardır.

Organizasyonların yönetimsel fonksiyonlarını desteklemek amacı ile bilgiyi toplayan, depolayan, üreten ve dağıtan bir mekanizma olan bilgi sistemleri; bilgiye kolayca erişip, bilgiyi daha verimli kullanabilme olanağı sağlamıştır [1]. Bilginin verimli ve sistematik kullanılmasında en yaygın kullanılan bilgi sistemlerinden biri Coğrafi Bilgi Sistemi (CBS)'dir. Kanada ve Amerika Birleşik Devletlerinde (ABD)'de 1960'lı yıllarda özel ve askeri amaçla geliştirilen CBS [2], artan ihtiyaç sonucunda çevre ve insan arasındaki etki-tepki sürecini konumsal olarak analiz etmede kullanılmaya başlayan bir veri tabanı yazılımıdır.

Günlük yaşamın vazgeçilmezi haline gelen mobil cihazlar, hayatın her aşamasındaki birçok faaliyet için etkin olarak kullanılmaktadır. Mobil cihaz teknolojisindeki gelişmelerin sağlamış olduğu önemli avantajlardan birisi, web ortamındaki harita altlıklarının her tür konu için kullanılabilmesidir. Konum belirleme ve gerçek zamanlı olarak sunma özelliğine sahip olan mobil cihazlar, değişik amaçlar için geliştirilen çeşitli yazılımlar aracılığı ile web tabanlı haritalar oluşturulmasına da altlık oluşturmaktadır [3]. Kullanıcılar tarafindan aktif olarak güncellenebilen bu harita verilerinin uygulamaciya sunulmasını sağlayan Leaflet Maps, Google Maps, Yahoo Maps, Bing Maps, MapQuest, OpenStreetMap ve Nokia Here Maps gibi çeşitli uygulamalar vardır. İnternet kullanımının çok yaygınlaşması ve internet hızının artması ile sürekli güncellenebilme özelliğine sahip bu web haritaların kullanımı da artış göstermiştir [4], [5].

Hyper Text Markup Language kelimelerinin kisaltmas1 olan HTML, 1980 yılinda CERN laboratuvarında çalışan araştırmacıların bilgi ve dokümanlarını kolayca paylaşabilmesi amacıyla geliştirilen bir sistemdir. Bu bilgisayar dili, sayfada bulunan metin, resim, ses, video gibi tüm içeriklerin yerleşim düzenini ve ziyaretçiye gösterimini sağlayan komutlar sunmaktadır. HTML komutları bir araya gelerek HTML sayfasını, bu sayfalarda bir araya gelerek web sitesini oluştururlar. Web sayfalarını oluşturmak ve düzenlemek için Not defteri, Notepad++, Dreamweaver, Visual Studio, Web Matrix ve NetBeans gibi birçok ücretli ve ücretsiz HTML Editörü vardır. Bu editörlerden profesyonel ".NET" uygulamaları geliştirmede en yaygın olarak kullanılanlardan birisi microsoft tarafindan üretilmiş olan Visual Studio editörüdür [6].

Leaflet, Web haritalama uygulamalarında 2011 yılından beri yaygın olarak kullanılmakta olan açık kaynak kodlu bir JavaScript kütüphanesidir. Basitlik ve performans ölçütleri dikkate alınarak üretilen Leaflet kolay kullanımı ve sürekli güncellenen modüler yapısı ile çevrimiçi haritalar için yazılım geliştirmede büyük kolaylıklar sağlamaktadır. Gerek mobil gerekse de masaüstü internet sağlayıcıları tarafindan rahatlıkla kullanılabilme avantajına sahiptir [7].

OpenStreetMap (OSM), arka planda Open Data Commons (ODC) lisansıyla hizmet veren çevrimiçi bir uzamsal veri tabanıdır. Açık kaynak yapısına sahip bu harita uygulaması, birçok mobil uygulamada kullanılabilmekte olup herhangi bir gelir beklentisi yoktur. OSM "Ücretsiz Wiki Dünya Haritası" sloganı ile 2004 yılında gündeme gelmiş olup günümüzde [8] foursquare, swarm gibi birçok sosyal 
medya uygulamasının yanı sıra bazı ülkelerin resmi uygulamalarında da harita sağlayıcı olarak kullanılmaktadır. Ayrıca MAPS.ME uygulaması sayesinde navigasyon imkanı da sunmaktadır [9]. Veri tabanı içerisinde coğrafi konumlarıyla beraber saklanan veriler, Mapnik adlı bir tarama motoru yardımıyla görselleştirilip haritaya dönüştürülür. $\mathrm{Bu}$ harita da, www.openstreetmap.org adresinden erişilebilen, Open Layers tabanlı bir ara yüzle kullanıcıların erişimine sunulmaktadır [10]. OpenStreetMap'te haritalar, kullanıcıların taşınabilir GPS alıcılarıyla kaydedip sisteme yükledikleri izlerin sayısallaştırılarak harita verisine dönüştürülmesiyle elde edilir. Öznitelik verileri, kullanıcının kendisinin topladığı verilere ya da kullanıcının yerel bilgilerine dayanarak girilmektedir. Bunlara ek olarak, açık kamu verileri, kullanım ve dağıtım izni olan tüm veriler de bu sistemde kaynak olarak kullanılabilmektedir. Sayısallaştırma ve veri üretim işlemleri, Landsat gibi kamuya açık uydu görüntüleri kullanarak gerçekleştirilebilmektedir [10]. Ayrıca Microsoft da, Bing Haritalarda kullandığı yüksek çözünürlüklü uydu görüntüleri kullanılarak veri üretimine izin verdiği için, söz konusu uydu görüntülerine OpenStreetMap düzenleyici ara yüzlerinde erişilebilmektedir. Güncellemelerin sistem sorumluları tarafından ya da sistem sorumlularının denetiminden geçmeden girilebiliyor olması çevredeki değişikliklerin gerçek zamanlıya yakın bir şekilde güncellenebilmesini sağlamaktadır.

Açık kaynak kodlu yazılımlar, incelenen konu ile ilgili verilerin herhangi bir kısıtlama ya da izin alınmadan herkesin erişimine açık olması ve kullanıcıların bu veriler üzerinde değişiklikler yaparak yeniden paylaşmasını teşvik eden bir geliştirme modelidir. [11] $\mathrm{Bu}$ konuda meydana gelen gelişmelerdeki kayda değer artış, bu sistemin kullanımına olan talebi de artırmıştır [12]. Bunlardan yararlanarak Filiz vd. (2013) [7] internet verisi iletişiminin sağlıklı olarak sağlanabildiği ve GPS sinyallerinin etkin olarak alınabildiği bölgelerde kullanıcıların birbirlerini harita üzerinde görebildiği bir takip sistemi geliştirmişlerdir. Yapılan bir çalışmada standart $1 / 50 \mathrm{~K}$ ölçekli vektör verilerinin üretimde OSM verilerinin kullanılmasının üretim süresini kısalttığı belirlenmiştir [13]. Benzer olarak Çabuk vd. (2015) [14] 1:50.000 ölçekli haritaların üretiminde OSM verilerinin üretimle birlikte kullanıldığında hem süreyi kısaltacağını hem de kaliteyi arttıracağını ifade etmişlerdir.

Kare kod, sınırlı alanlarda sınırsız bilgi, mesaj, video ve her türlü içerik aktarımı sağlayarak bilgiye erişim noktasında bağlantı oluşturan bir araçtır. Pratiklik, hızlılık ve düşük maliyet gibi özellikleri sayesinde otomotiv, lojistik, sağlık, turizm, sosyal medya gibi pek çok sektörde yaygın biçimde kullanılmaktadır [15], [16]. Kare kod teknolojisi dâhili kamera özelliğine sahip mobil araçlar ve kare kod okuyucu uygulamalar ile kullanılmaktadır [17]. Bunlar mobil cihazların kameralarıyla okunabilen özel matris ya da yatay ve dikey yönde bilgi verebilen iki boyutlu bir barkod türü olup geleneksel barkod türlerine göre daha hızlı çalışır [18] [19]. Kare kod, cihaza yüklenen uygulama tarafından hızlıca çözümlenebilmekte ve kullanıcılar, kare kod içerisine şifrelenmiş bilgiyi cihazlarının ekranlarında görebilme, mobil web sayfalarına ya da e-posta adresine yönlendirilme ya da kısa mesaj (SMS) şeklinde ulaşabilme imkanına sahip olmaktadır [20], [21]. Polat (2014) [22] kare kod teknolojisinin; adres ve yapı bilgilerinin paylaşımı, yer kontrol noktalarının tanımlanması, taşınmazların yerlerinin harita üzerinde gösterimi, taşınmazların pazarlanması ile haritaların ve paftaların birleştirilmesi işlerinde kullanımının taşınmaz malların yönetimini kolaylaştırdığını ifade etmiştir.

Günümüzde, şehir yaşamındaki koşturmaca, stres, betonlaşma, trafik ve kirlilik gibi olumsuzluklar insanların yaşam kalitesini önemli oranda olumsuz etkilemektedir. Ulrich vd. (1991) [23] yoğun bitki örtüsü bulunan alanların kişilerde fiziksel ve psikolojik rahatlama duygusu uyandırması nedeniyle şehirlerde yaşayan insanların bitki topluluklarının bulundukları alanları ziyaret etme isteklerinin arttığını belirlemiştir. Şehirlerde yaşayan insanlar bu isteklerini turistik ya da dinlenme amaçlı olarak; kent ormanları, milli park, tabiat parkı, botanik parkı, arboretum ya da çok sayıda bitki türü barındıran bunlara benzer alanları ziyaret ederek gidermektedirler.

Doğu Karadeniz Bölgesinde yer alan Trabzon ilinde şehir merkezine yakın olan ve çok sayıda ziyaretçi alan Altındere milli parkı, Trabzon botanik parkı, şehir parkları, Karadeniz Teknik Üniversitesi (KTÜ) ve Trabzon Üniversitesi kampüslerinde çeşitli incelemeler yapılmıştır. Yapılan 
incelemelerde ziyaretçilerin ve kullanıcıların birçoğunun bu alanlara bitki çeşitliliğini görmek ve doğal güzelliği izlemek için geldikleri gözlemlenmiştir. Ziyaretçi ve katılımcıların büyük bölümü alanlarda bulunan bitki türlerini tanımadıkları ancak bitkiler hakkında bilgi sahibi olmak istemekteler. $\mathrm{Bu}$ çalışmada, gelişen teknoloji ile kullanımı yaygınlaşmakta olan açık bilgi sistemlerinden yararlanarak bitkilerin botanik özelliklerini içeren kare kodlar oluşturulması ve kullanıcıların mobil cihazları aracılığıyla bu bilgilere direk ulaşımını sağlayan bir program geliştirilmesi amaçlanmıştır.

\section{MATERYAL VE YÖNTEM}

Çalışma kapsamında araştırma alanı olarak Türkiye'nin Doğu Karadeniz bölgesindeki Trabzon ili, Ortahisar ilçesi sınırları içerisinde yer alan $40.9875^{\circ}-41.0001^{\circ} \mathrm{N}$ ve $39.7637^{\circ}-39.7786^{\circ} \mathrm{E}$ coğrafi koordinatlarındaki KTÜ Kanuni Yerleşkesi seçilmiştir (Şekil 1).

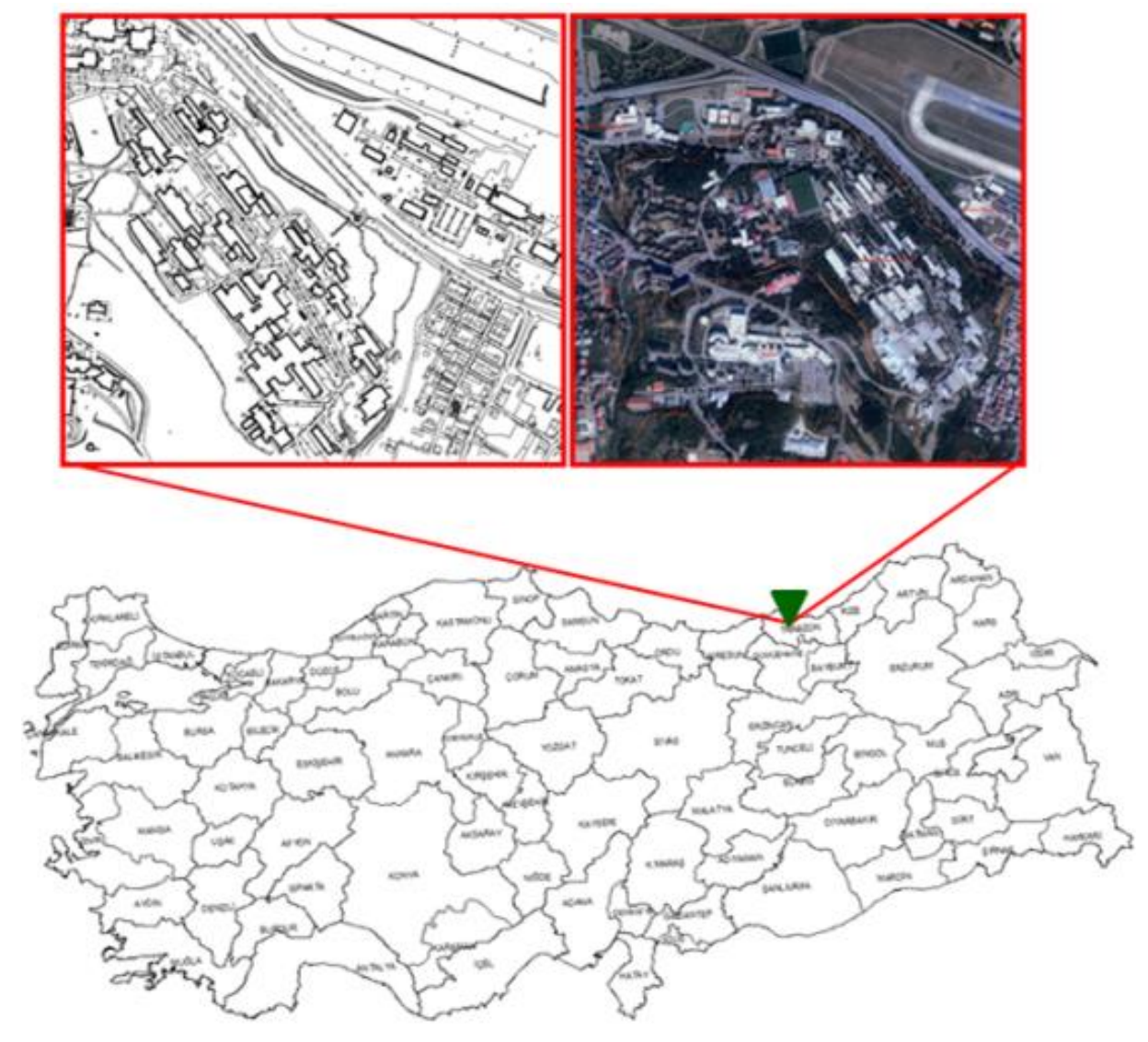

Şekil 1. Karadeniz Teknik Üniversitesi Kanuni Kampüsü (1/2000 Ölçekli Orto Görüntü)

İstanbul ve Ankara dışında kurulan ilk üniversite olan KTÜ'nin Kanuni Yerleşkesi; Rektörlük, 10 Fakülte, 5 Enstitü, 3 Yüksekokul ve araştırma merkezleri bulunan 1.061.118,76 $\mathrm{m}^{2}$ büyüklüğ̈̈nde bir alana sahiptir. Kampüs; yaklaşık 40206 öğrenci, 2136 öğretim üyesi ve 1629 idari personel, 1699 Sözleşmeli personel ve işçiler ile toplam 45670 kişilik bir kullanıcı kitlesine sahiptir [24].

Yerleşke değişik yörelerden, çok sayıda angiospermae ve gymnospermae türde ağaç, ağaççık ve çalı barındıran bir arboretum görüntüsüne sahiptir [25] [26]. Çalışma alanı içerisinde bulunan başlıca ağaç ve ağaççıklar; Acer campestre L., A. glabrum Torr., Aesculus hippocastanum L., Betula nigra L., Celtis orientalis L., Cupressus arizonica Greene., C. sempervirens L., Cotinus coggygria (Scop.), Fraxinus americana L., F. texensis (A.Gray) Sarg., F. ornus L., Elaeagnus rhamnoides (L.) A. Nelson, Ginkgo biloba L., Koelreuteria paniculata Laxm., Liriodendron tulipifera L., Picea pungens Engelm., Pinus pinea L., P. sylvestris L., P. strobus L., Quercus macrocarpa Michx., Q. nigra L., Q. 
rubra L., Robinia pseudoacaia L., Sophora japonica L., Syringa vulgaris L., Tamarix tetrandra Pallas ex Bieb., Taxodium distichum (L.) Rich. ve Taxus baccata L. olarak sıralanabilir [27]. Bu özelliği nedeniyle hem kullanıcılar (öğrenci ve öğretim üyeleri) hem de şehir halkı tarafından dinlenme ve gezinti amaçli olarak ziyaret edilmektedir.

Çalışma kapsamında yerleşkede yapılan arazi gözlemleri ile en yaygın olarak bulunan ağaç türlerinden 13 tanesi seçilerek SONY DSC-H300 marka fotoğraf makinesi ile fotoğrafları çekilmiş ve GARMIN GPSmap76Cx ile konumları belirlenmiştir (Şekil 2). Sonrasında literatür taraması ile belirlenen her bir ağaç türünün botanik özelliklerini içeren veri tablosu oluşturulmuştur.

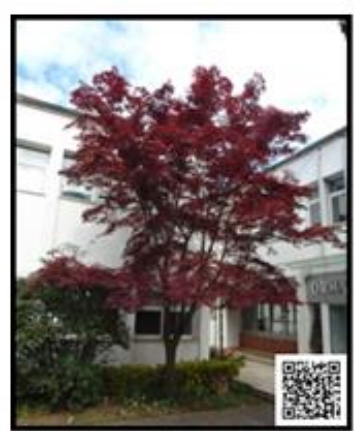

Acer palmatum Raf.

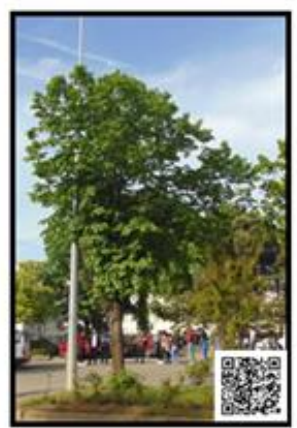

Tilia platyphyllos Scop.

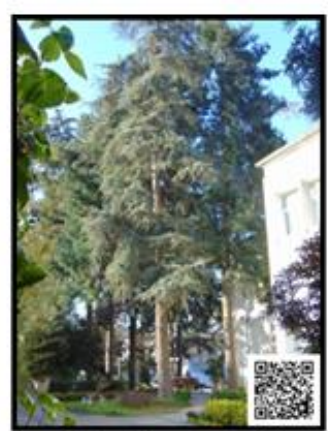

Cedrus libani A. Rich.

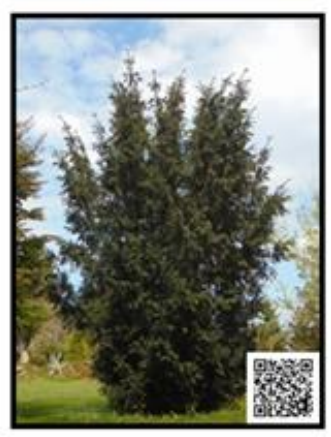

Taxus baccata $L$.



Ginko biloba L.

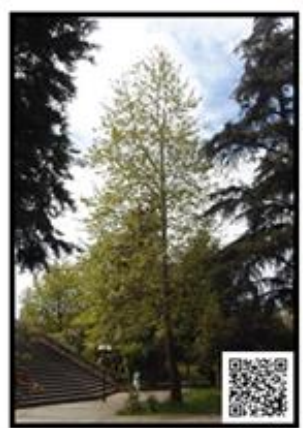

Platamus orientalis $L$

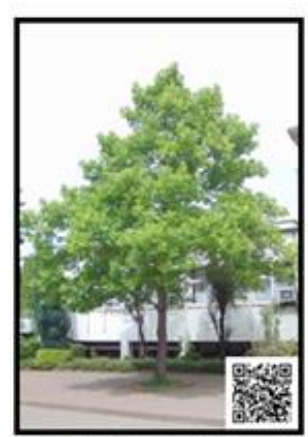

Liriodendron tulipifera $L$.

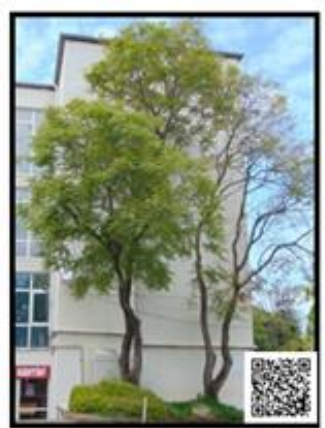

Koelreuteria pamiculata Laxm.

Şekil 2. İncelenen ağaç türlerinin bazıları

Kare kod oluşturulacak her bir ağaç için; oluşturulma tarihi, bitki sınıfi, bitki boyutu ve bitki sıra numarasını içeren bir bitki pasaport numarası geliştirilmiştir (Şekil 3).

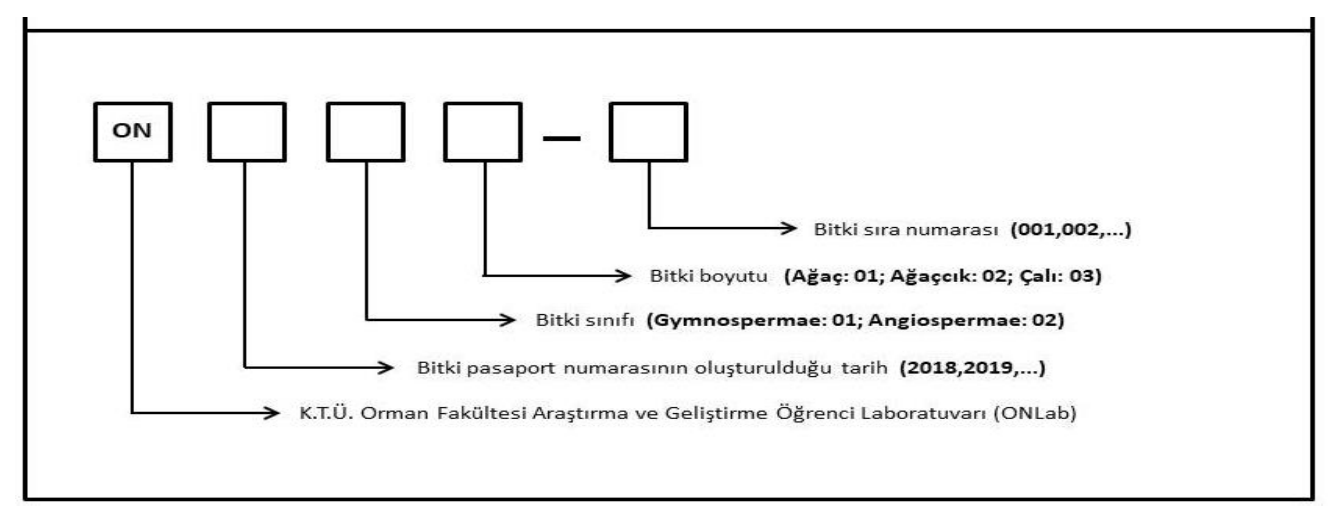

Şekil 3. Bitki pasaport numarası tasarımı

Sonrasında bitkinin botanik özellikleri, görselleri ve konumlarını barındıran kare kodlar hazırlanarak bitki bilgi etiketi oluşturulmuş ve ilgili ağaçlar üzerine yerleştirilmiştir. Kare kod içerisindeki bilgilerin şifresiz ve açık bir şekilde kullanıcıya sunulabilmesi için Leaflet ve OpenStreetMap açık kod 
sistemlerinden yararlanarak KTÜ Onlab web ara yüzündeki Visual Studio Code editörü üzerinde HTML olarak bir program yazılmıştır.

\section{UYGULAMA}

Web - Bitki Bilgi Sistemi uygulamasının geliştirilmesinde izlenen süreç; arazi çalışmaları, ofis çalışmaları ve uygulama olmak üzere üç ana aşamadan oluşmaktadır (Şekil 4).
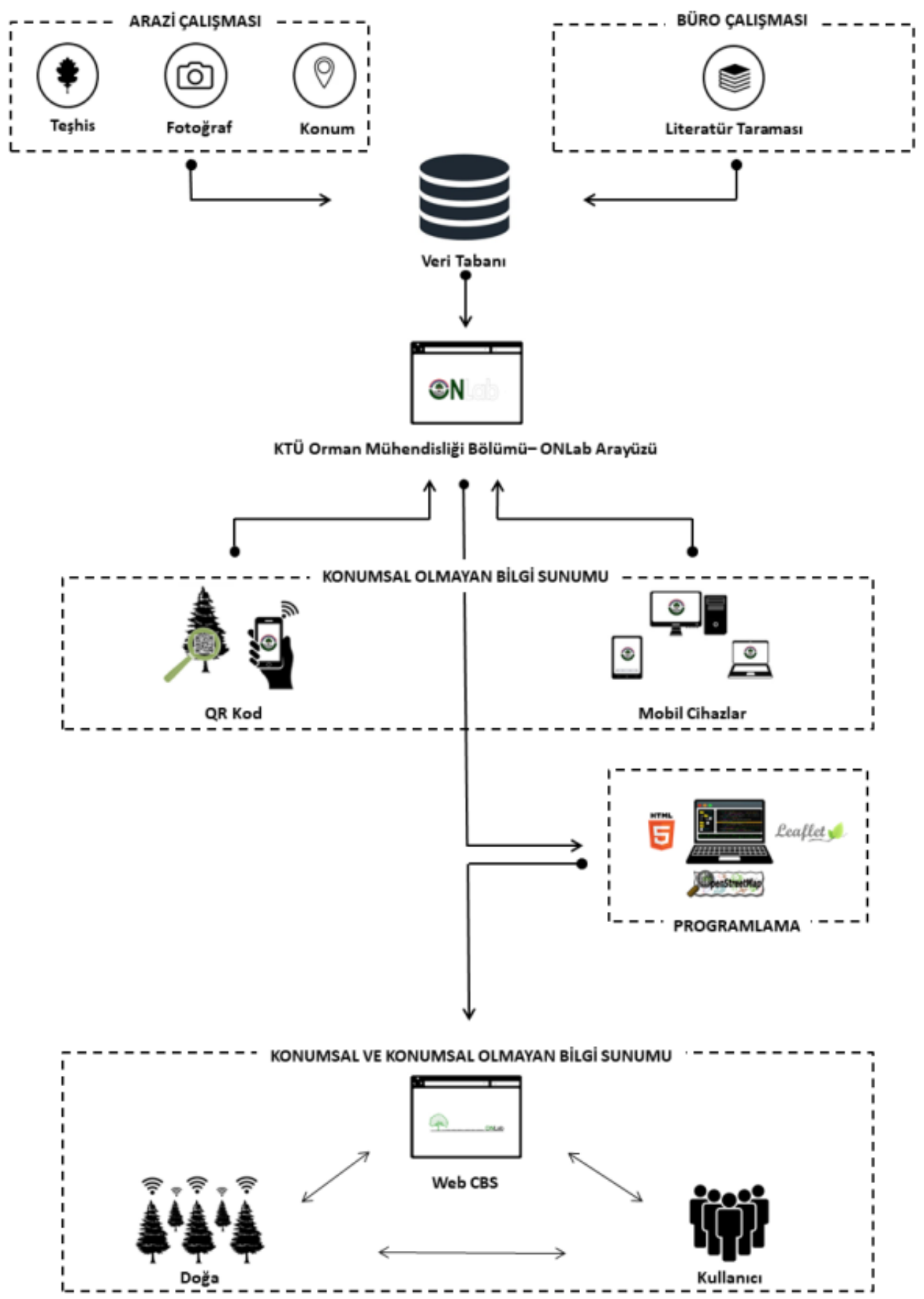

Şekil 4. Süreç akışl 
Şekil 4'te gösterilen süreç akışında arazi çalışmaları bölümünde öncelikle kampüs gezilerek en yaygın olarak bulunan ve kullanıcıların/ziyaretçilerin en çok dikkatini çeken ana ağaç türlerinden 13 tanesi seçilmiştir. Teşhis edilen türlerin kozalak/meyve, yaprak, gövde kabuğu ve habitus fotoğrafları çekilmiş, konumları GPS ile belirlenmiş ve kayıt edilmiştir (Tablo 1).

Tablo 1. Incelenen ă̆aç türleri ve konumları

\begin{tabular}{lllll}
\multirow{2}{*}{ No } & Tür Adı (Türkçe) & Tür Ad1 (Latince) & \multicolumn{2}{l}{ Koordinatlar (UTM-WGS84) } \\
\cline { 4 - 5 } & & Enlem & Boylam \\
\hline 1 & Japon Akçaağacı & Acer palmatum Raf & $40.99288333^{\circ}$ & $39.77651667^{\circ}$ \\
\hline 2 & Toros Sediri & Cedrus libani A. Rich. & $40.99291667^{\circ}$ & $39.77638333^{\circ}$ \\
\hline 3 & Yeşil Duglas & Pseudotsuga menziesii (Mirb.) & $40.993^{\circ}$ & $39.7765^{\circ}$ \\
\hline 4 & Kizılçam & Pinus brutia Ten. & $40.9931^{\circ}$ & $39.7764^{\circ}$ \\
\hline 5 & Doğu Çınarı & Platanus orientalis L. & $40.99323333^{\circ}$ & $39.7764^{\circ}$ \\
\hline 6 & Mabet Ağac1 & Ginko biloba L. & $40.99271667^{\circ}$ & $39.77648333^{\circ}$ \\
\hline 7 & Arizona Servisi & Cupressus arizonica Greene. & $40.99315^{\circ}$ & $39.77643333^{\circ}$ \\
\hline 8 & Amerikan Lale Ağacı & Liriodendron tulipifera L. & $40.99265^{\circ}$ & $39.77653333^{\circ}$ \\
\hline 9 & Büyük Yapraklı Ihlamur & Tilia platyphyllos Scop. & $40.9924667^{\circ}$ & $39.7765^{\circ}$ \\
\hline 10 & Güvey Kandili & Koelreuteria paniculata Laxm. & $40.99285^{\circ}$ & $39.7772^{\circ}$ \\
\hline 11 & Gürgen & Carpinus betulus L. & $40.99308333^{\circ}$ & $39.77713333^{\circ}$ \\
\hline 12 & Porsuk & Taxus baccata L. & $40.99321667^{\circ}$ & $39.777^{\circ}$ \\
\hline 13 & Beyaz Çiçekli At Kestanesi & Aesculus hippocastanum L. & $40.9935^{\circ}$ & $39.7768^{\circ}$
\end{tabular}

Öncelikle arazi çalışmalarında belirlenen ağaç türlerinin her biri için bir pasaport numarası geliştirilmiş ve literatür taraması yapılarak genel botanik özellikleri belirlenmiştir [28] [29] [30] [31] [32] [33]. Bitkiler hakkında elde edilen genel ve detaylı bilgiler belirli bir formatta sadeleştirilerek herkes tarafından anlaşılabilir bir veri tabanı oluşturulmuştur (Şekil 5).



Şekil 5. Bitki türleri için genel veri tabanının oluşturulması

Çalışma kapsamında bitki türleri için belirlenen öznitelik bilgileri (görseller, koordinatları, botanik özellikleri ve pasaport numarası) KTÜ Orman Mühendisliği Bölümü web sayfasının ONLab ara yüzünde depo edilerek URL'nin içinde verildiği kare kodlar hazırlanmıș ve ağaçlar üzerine takılmıștır (Şekil 6). 


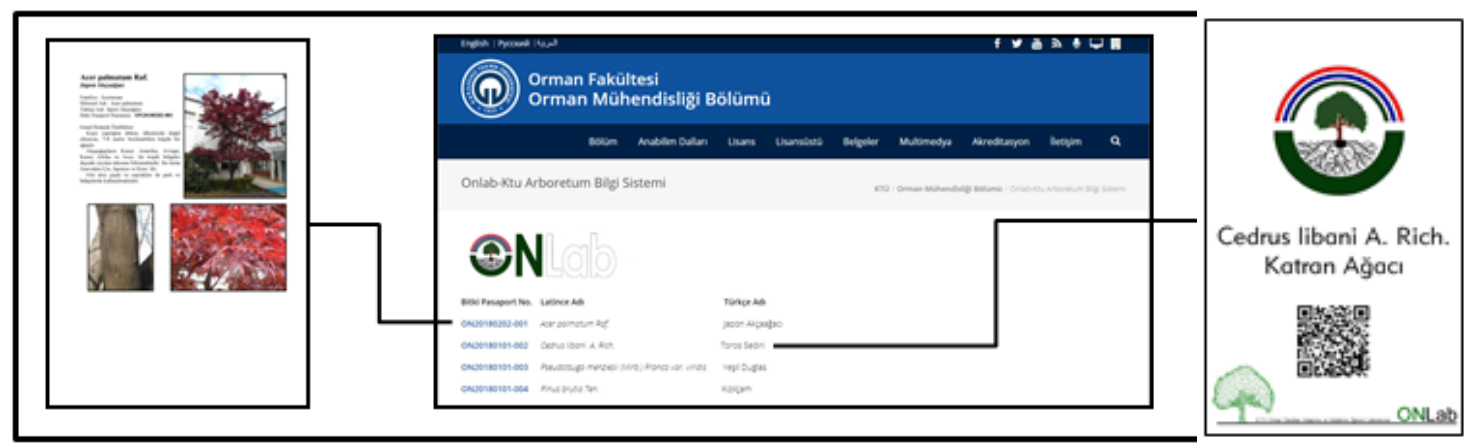

Şekil 6. Karekod ile öznitelik bilginin elde edilmesi

Çalışma kapsamında bitki hakkındaki öznitelik bilgilerinin anlamlı olarak sunulabilmesi için HTML Programlama dilinde, Leaflet java script kütüphanesinden yararlanarak OpenStreetMap harita altlığ1 kullanılarak web ortamında bir haritalama gerçekleştirilmiştir. Kullanıcı ve ziyaretçiler kablosuz internet ve mobil cihazda bulunan kare kod okuyucu uygulaması aracılığıyla kısa sürede bitki hakkında öznitelik bilgiye ulaşması mümkündür.

Çalışmada java script kütüphanesi olan Leaflet sağlayıcısı sayesinde OpenStreetMap_Mapnik (Şekil 7-a) ve OpenTopoMap (Şekil 7-b) harita katmanları oluşturulmuş ve harita üzerindeki bitkiler farklı renkteki ikonlar ile Gymnospermae ve Angiospermae olmak üzere iki sınıfta gösterilmiştir.

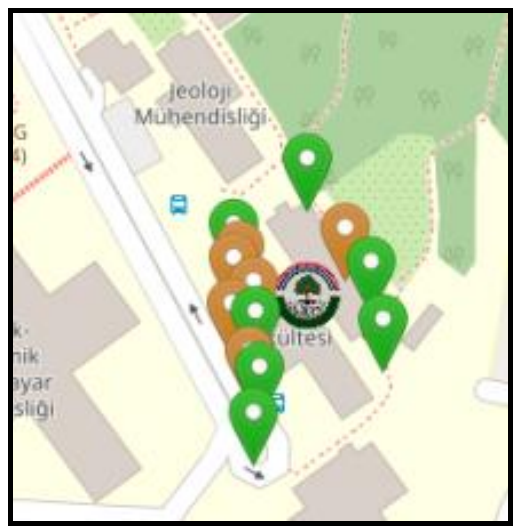

(a)

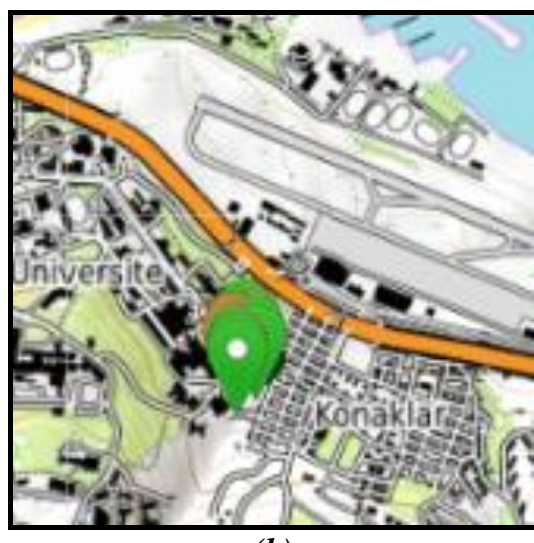

(b)

Şekil 7. OpenStreetMap_Mapnik (a) ve OpenTopoMap (b) harita katmanlarl

Web-Bitki Bilgi Sistemi uygulamasında her bir nokta için koordinat bilgileri, bitki sınıfina göre konum işaret rengi, konum işaretine ait açılır pencere, bitkinin ismi ve öznitelik bilgilerini elde etme komutları yazılmıştır (Şekil 8).
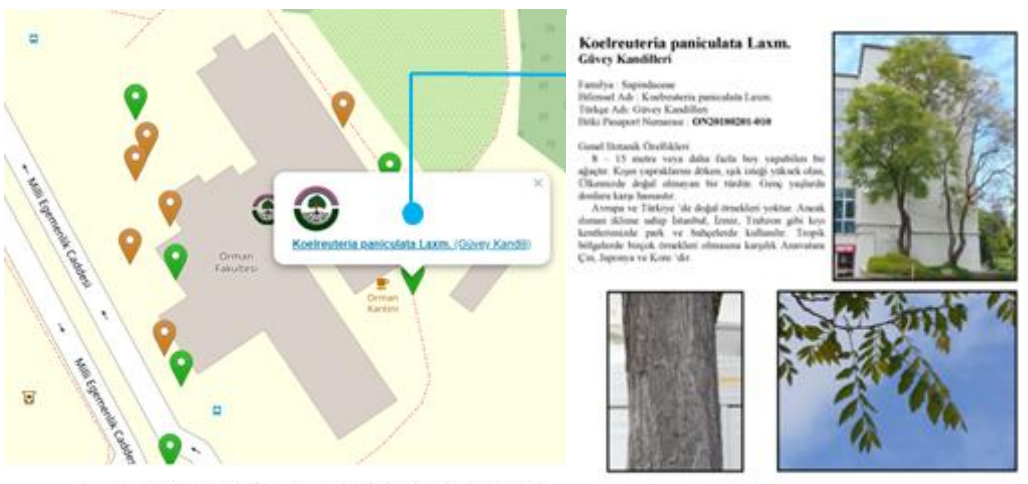

[UTM - wGS84]Bitki Koordinat (N,E):40.99285 $39.7772^{\circ}$

Şekil 8. Açılır pencere içerisindeki bitkilere ait öznitelik bilgilerin sunumu 


\section{IV.SONUC}

Bitki Bilgi Sisteminin geliştirilmesindeki ana amaç; bitki topluluklarının yoğun olarak bulunduğu alanlara gelen her sektörden kişinin gördükleri ve merak ettikleri bitki türleri hakkında meraklarını giderebilmelerine katkı sunmaktır. Etraflarında gördükleri değişik bitki türleri hakkında anında bilgi edinebilmeleri ve o bilgileri gözlemleyebilmeleri insanların doğaya bakış açılarına yeni yaklaşımlar katabilmektedir. Bu çalışma kapsamında çok sayıda değişik türlerde bitki topluluğuna ve yoğun kullanıcı/ziyaretçi kitlesine sahip KTÜ Kanuni Yerleşkesindeki ana bitki türleri için bir bitki bilgi sistemi geliştirilmiştir. Açık kaynak sistemi üzerinden yazılan bu sisteme internet olan ortamda her türlü kameralı mobil cihazlar ile kolaylıkla ulaşılabilmektedir. Bilgi sistemi üzerinde bitkinin genel özelliklerinin yanı sıra konum bilgilerinin de bulunması, kullanıcıyı bulunduğu yer ile ilgili ek bir bilgilendirme de sağlamaktadır.

Çalışma kapsamında sınırlı sayıda bitki türü için veri tabanı oluşturularak geliştirilen web tabanlı bitki bilgi sistemi kampüsün tamamı için genişletilerek alanda bulunan bitki türlerinin envanterinin yapılabilmesine katkı sunacaktır. Böylece hangi bitki türünden kaçar adet bulunduğu ve kampüsün gerek peyzaj planlaması gerekse de orman mühendisliği, peyzaj mimarlığı ve biyoloji gibi bölümler için eğitim amaçlı kullanımlarda ihtiyaç duyulabilecek yeniliklere karar verilmesine önemli katkı sunacaktır. Ağaçlar üzerine yerleştirilen kare kodlu bitki bilgi etiketi ile bitkiler hakkında geniş çaplı bilgilere ulaşılması gerek kullanıcılar gerekse konu ile ilgili bölümlerde okuyan öğrencilere anında bilgi sağlanması mümkün olacaktır. Öğrencilerin bitkilerin teşhis edilmesi ya da üzerinde çalışmak için yaprak, meyve ya da dalları koparılarak verilen zararlar azaltılabilecektir. Ayrıca son yıllarda oldukça önem kazanan biyoçeşitlilik kavramı göz önüne alınarak alanın biyoçeşitlilik döküm karneleri oluşturulabilecek ve biyoçeşitliliğin sürdürülebilirliği için koruma stratejileri geliştirilebilecektir.

Web tabanlı Bitki Bilgi Sistemi, barındırdığı bitkiler için ilgi gören üniversite kampüsleri, milli park, tabiat parkı, botanik parkı ve arboretum gibi alanlar için örnek teşkil edecektir. Böyle alanlara uygun bitki bilgi sistemlerinin geliştirilmesi ziyaretçilerin ilgisini ve doğaya bakış açısını olumlu yönde etkileyebilecektir.

TEȘEKKÜR: $\mathrm{Bu}$ çalışma kapsamında gerçekleştirilen uygulamanın web sürümü (http://www.ktu.edu.tr/ormanmuhendisligi-onlabprojeler) için ihtiyaç duyulan web sayfası Karadeniz Teknik Üniversitesi, Orman Mühendisliği Bölümü web sayfasında OnLab adı altında oluşturulmuştur. Bu kapsamda bize destek olan Karadeniz Teknik Üniversitesi Rektörlüğü, Orman Fakültesi Dekanlığı ve Orman Mühendisliği Bölüm Başkanlığına teşekkür ederiz. Çalışma kapsamında kullanılan bitki türlerinin teşhisinde katkı sunan Doç. Dr. Sefa AKBULUT’a teşekkür ederiz.

\section{KAYNAKLAR}

[1] T. Yomralığlu, Coğrafi Bilgi Sistemleri Temel Kavramlar ve Uygulamalar, 1. Bask1, Trabzon, Türkiye: Seçil Ofset, 2000, ss. 1-1045.

[2] İ. Karataş ve İ. Kırbaş, "Özgür ve açık kaynak kod coğrafi bilgi sistemi yazılımlarının karşılaştırmalı değerlendirmesi”, XVII. Akademik Bilişim Konferansı (AB2015), Eskişehir, Türkiye, 2015, ss. 68-74.

[3] O. Özer ve K. Kalkan, "Harita gösterimlerinde yeni trendler ve teknolojiler", 6. Uzaktan Algılama-CBS Sempozyumu (UZAL-CBS 2016), Adana, Türkiye, 2016, ss. 93-97. 
[4] J. Van den Worm, "Web Map Design in Practice", Web Cartography: Developments and Prospects (eds. M.-J. Kraak and A. Brown), 1. Bask1, London, England: Taylor \& Francis, 2003, ss. 87-108.

[5] M. You, C.W. Chen, H. Liu ve H. Lin, "A Usability Evaluation of Web Map Zoom and Pan Functions", International Journal of Design, c. 1, s. 1, ss. 15-25, 2007.

[6] F. Erdinç, Yeni Başlayanlar İçin JavaScript, 1. Baskı, İstanbul, Türkiye: Abaküs Kitap Yayın Pazarlama, ISBN: 978-605-9129-36-7, 2016.

[7] G. Filiz, D. Maktav, K. Kalkan ve O. Özer, "Mobil platformlar üzerinden gerçek zamanlı ekip takip sistemi”, TMMOB Coğrafi Bilgi Sistemleri Kongresi, Ankara, Türkiye, 2013. ss. 1-5.

[8] M. Haklay ve P. Weber, "OpenStreetMap: User Generated Street Maps", Pervasive Computing IEEE, c. 7, s. 4, ss. 12-18, 2008.

[9] H. Kocaman. (2019, 23 Mayı). Open Street Map nedir? [Online]. Erişim: https://www.hakankocaman.com/open-street-map-nedir

[10] H.C. Ünen, O.M. Yılmaz ve O. Güngör, "Özgür harita: OpenStreetMap”, TMMOB Coğrafi Bilgi Sistemleri Kongresi, Ankara, Türkiye, 2013, ss. 1-6.

[11] A. Gerber, O. Molefo ve A. Van der Merwe, "Documenting open source migration processes for re-use", SAICSIT 2010 Conference - Fountains of Computing Research, 2010, ss. 75 - 85.

[12] F. Sarı, A. Erdi ve O.S. Kırtıloğlu, "İnternet tabanlı coğrafi bilgi sistemi uygulamalarında Geoserver-Arcgis server ve google map API entegrasyonu”, TMMOB Harita ve Kadastro Mühendisleri Odası 13. Türkiye Harita Bilimsel ve Teknik Kurultayı, Ankara, Türkiye, 2011, ss. 140145 .

[13] S. Çabuk, M. Erdoğan ve E. Önal, "Open Street Map Verilerinden Yararlanılarak 1/50K Ölçekli Harita Üretilebilirliğinin Araştırılması”, Harita Dergisi, c. 154, ss. 26-34, 2015.

[14] S. Çabuk, M. Erdoğan, O. Eker, M. Kaya, H. Ardıç ve E. Önal, "Topoğrafik veri üretiminde open street map verilerinin kullanımı", TUFUAB VIII. Teknik Sempozyumu, Konya, Türkiye, 2015, ss. 316-319.

[15] Fortune. (2019, 15 Şubat). Foursquare just predicted chipotle's sales will plummet [Online]. Erişim: http://fortune.com/2016/04/15/chipotle-foursquare-swarm/ .

[16] K. Kalkan, "Konum ve Pazarlamanın Birleştiği Yer: Geo-Marketing”, Satın Alma Dergisi, c. 2, ss. 15, 2014.

[17] C. Aktaş ve B. Çaycı, "QR Kodun Mobil Eğitimde Yeni Eğitim Yöntemlerinin Geliştirilmesine Katkısı”, Global Media Journal, c. 119, ss. 1-19, 2013.

[18] A. Ramsden, The use of $Q R$ codes in education: A getting started guide for academics, Working Paper, Bath, UK, 2008, ss. 9.

[19] D. Lorenzi, J. Vaidya, S. Chunb, B. Shafiq ve V. Atluri, "Enhancing The Government Service Experience Through QR Codes on Mobile Platforms", Government Information Quarterly, c. 31, ss. 6-16, 2014.

[20] C.Y. Law ve S. So, "QR Codes in Education", Journal of Educational Technology Development and Exchange, c. 3, s. 1, ss. 85-100, 2010. 
[21] A. Ramsden ve L. Jordan, Are students ready for QR codes? Findings from a student survey at the University of Bath, Working Paper, 1st Publication, Bath, UK, 2009, ss. 6.

[22] Z.A. Polat, "Karekod teknolojisinin mesleğimizdeki olası kullanımları üzerine düşünceler", V. Uzaktan Algilama-CBS Sempozyumu (UZAL-CBS 2014), İstanbul, Türkiye, 2014, ss. 1-8.

[23] R.S. Ulrich, R.F. Simons, B.D. Losito, E. Fiorito, M.A. Miles ve M. Zelson, "Stress Recovery During Exposure to Natural and Urban Environments". Journal of Environmental Psychology, c. 11, ss. 201-230, 1991.

[24] Karadeniz Teknik Üniversitesi (KTÜ) Strateji Geliştirme Daire Başkanlığı, Karadeniz Teknik Üniversitesi 2018 Yılı İdare Faaliyet Raporu, 1. Bask1, Trabzon, Türkiye: KTÜ Matbas1, 2019, ss. 197. Erişim: http://www.ktu.edu.tr/sgdb-ktuidarefaaliyetraporlari

[25] T. Düzenli, E. Tarakçı Eren, H. Baltacı ve E. Aktürk, "Bitkisel Peyzaj Tasarımında Renk Tercihleri: KTÜ Kanuni Kampüsü Örneği”, Uluslararast Sosyal Araştırmalar Dergisi, c. 11, s. 55, ss. 1082-1091, 2018.

[26] N. Güneroğlu ve M. Bekar, "Evaluation of Open Green Areas in Terms of Planting Design Criteria; The Case Study of KTÜ Kanuni Campus", Social Sciences Studies Journal, c. 4, s. 16, ss. 1113-1120, 2018.

[27] E. Bayramoğlu, "Sürdürülebilir Peyzaj Düzenleme Yaklaşımı: KTÜ Kanuni Kampüsü’nün Xeriscape Açısından Değerlendirilmesi”, Çoruh Üniversitesi Orman Fakültesi Dergisi, c. 17, s. 2, ss. 119-127, 2016.

[28] H. Kahveci, C. Acar ve Ö.C. Hergül, "Doğu Karadeniz Kıyı Alanlarında Yetişen Perennial (Çok Yıllık Otsu) Bitkilerin Peyzaj Mimarlığı Açısından Değerlendirilmesi”, International Journal of Social and Humanities Sciences Research, c. 5, s. 31, ss. 4568-4579, 2018.

[29] Y. Akman, O. Ketenoğlu, L. Kurt, F. Kurt ve S.T. Körüklü, Gymnospermae (Açık Tohumlular), 1. Baskı, İstanbul, Türkiye: Ajans-Türk Gazetecilik Matbaacılık. ISBN: 978-975-974362-0, 2012.

[30] G.M. Mamıkoğlu, Türkiye’nin A ğaç ve Çalıları, İstanbul, Türkiye: NTV Yayınları, ISBN: 978-605-5813- 49-9, 2010.

[31] G. Ceylan, Dış Mekan Süs Bitkileri Ve Peyzajda Kullanımları, İstanbul, Türkiye: Flora Yayınları, ISBN: 975-6884-03-7, 2004.

[32] R. Anşin ve Z.C. Özkan, Tohumlu Bitkiler (Spermatophyta) Odunsu Taksonlar, 2. Bask1, Trabzon, Türkiye: KTÜ Orman Fakültesi Yayınları, 1997, ss. 512.

[33] World Flora Online Consortium (WFOC). (2019, 27 May1s). An online flora of all known plants: Supporting the Global Strategy for Plant Conservation [Online]. Erişim: http://www.worldfloraonline.org/ 